\title{
SISTEMA REVELAR: educação, fotografia e interação no Jardim Botânico do Rio de Janeiro
}

\author{
Juliano Caldeira Kestenberg \\ Escola Superior de Desenho Industrial / Uerj \\ info@julianokestenberg.com \\ Washington Dias Lessa \\ Escola Superior de Desenho Industrial / Uerj \\ washington.lessa@gmail.com \\ Luiz Velho \\ Instituto Nacional de Matemática Pura e Aplicada \\ Ivelho@impa.br
}

Resumo: Em meio à rápida propagação de tecnologias de mídia que tornam possível produzir, arquivar, se apropriar e recircular conteúdo informacional, uma cultura participativa vem emergindo nos dias atuais. Se faz presente uma lógica de colaboração mediada por ferramentas técnicas que estruturam o conhecimento em rede. Nesse contexto, o museu, enquanto agência de representação sociocultural, se esforça no sentido de atualizar-se. Nesta pesquisa, sugere-se que a interação participativa de caráter social é um caminho para renovar e ampliar as narrativas culturais elaboradas pelos museus, em sua relação comunicacional com o público. Foi elaborado, então, o sistema Revelar: um modelo preliminar que se propõe a investigar o design de participação em contexto museológico. 0 sistema, que tem como palco de ações o complexo do Jardim Botânico do Rio de Janeiro, pressupõe a participação de estudantes de Ensino Médio em uma atividade programada pela equipe do Museu do Meio Ambiente. A matéria de contribuição dos alunos participantes é a fotografia produzida a partir do uso de dispositivos móveis.

Palavras-chave: Ação educativa, Design de participação, Mobile imaging, Jardim Botânico do Rio de Janeiro, Museu do Meio Ambiente.

Abstract: A participatory culture is emerging amid the fast propagation of
media technologies that make it possible to produce, archive, appropriate
and recirculate informational content. A collaboration logic is observed,
mediated by technical tools that structure the networked knowledge. In this
context, the museum performs an effort in order to update itself as an
agency of sociocultural representation. In this research, we maintain that
the social participatory interaction is a path to renew and expand the 
cultural narratives developed by museums, in respect to its communicational relationship with the audience. Therefore, a system called Revelar was devised: a preliminary model which aims at investigating participation design within a museological context. The system, which is located in Rio de Janeiro Botanical Garden, presupposes the participation of high school students in an activity elaborated by the Environment Museum team. Participants contribute with photographs captured with mobile devices.

Keywords: Educational action, Designing for participation, Mobile imaging, Rio de Janeiro Botanical Garden, Environment Museum.

\title{
1. INTRODUÇÃO
}

Em um panorama social caracterizado pelo desenvolvimento de projetos colaborativos que se utilizam de mídias digitais em rede, o museu, enquanto agência de representação sociocultural, se vê diante do desafio de atualizar-se, servindo de base para experiências que envolvam educação não-formal e entretenimento.

Com a difusão da World Wide Web, as possibilidades de acesso à informação e o repertório de recursos de linguagem para a criação se multiplicaram. Nesta investigação, sugerimos que a interação participativa de visitantes no ambiente de museu é um caminho para renovar e ampliar as narrativas culturais elaboradas por tais instituições para as comunidades a que se propõem servir. Nessa perspectiva, apoiar a participação do público significa confiar nas habilidades dos visitantes como criadores e redistribuidores de conteúdo. E esse apoio certamente requer a concepção de um sistema que forneça suporte à participação, balizando a atuação dos agentes envolvidos.

De acordo com a pesquisadora Nina Simon (2010, localização 125 de 7226), não basta, portanto, o museu desejar que uma experiência participativa aconteça em seu ambiente. É a atividade de projeto que vai conferir condições para que isso seja possível:

\begin{abstract}
Essa não é uma questão de intenção ou desejo; é uma questão de design. [...] Ter sucesso com um modelo participativo significa encontrar caminhos para projetar plataformas participativas de maneira tal que o conteúdo que amadores criam e compartilham seja comunicado e exibido atrativamente. ${ }^{1}$ (tradução nossa)
\end{abstract}

Assim sendo, além de elaborar o conteúdo para as suas exposições, os museus que optem por uma abordagem participativa devem oferecer oportunidades bem estruturadas para que seus visitantes compartilhem seus conhecimentos e experiências. Está em cena, portanto, o design de participação em contexto de museus. Esta oportunidade projetual de trabalhar a informação em processo traz, a reboque, uma série de questões, dentre as quais: a) como estimular o envolvimento das pessoas?; b) de que maneiras pode se dar a colaboração do público?; c) como filtrar e exibir o que for produzido? (mecanismos de moderação e validação do

\footnotetext{
1 "This is not a question of intention or desire; it's a question of design. [...] Being successful with a participatory model means finding ways to design participatory platforms so the content that amateurs create and share is communicated and displayed attractively." Nina Simon, The participatory museum.
} 
conteúdo); d) quais estratégias de apresentação interativa do conteúdo são capazes de contemplar os não-participantes, que representam a maior porção do espectro de visitantes?; e) como facilitar a comunicação entre a equipe de profissionais do museu e os visitantes?

Nesta pesquisa, foi elaborado o sistema Revelar, cujo objetivo é a investigação das potencialidades de projeto decorrentes do exercício do design de participação em contexto museológico. Resumidamente, pode-se afirmar que o sistema prevê ações coletivas em museu, e tem na fotografia produzida por meio do uso de dispositivos móveis o elo de conexão que incentiva e viabiliza a participação dos visitantes.

O palco principal para as ações roteirizadas é o complexo do Jardim Botânico do Rio de Janeiro. Lá, estudantes de Ensino Médio participariam de uma atividade programada pela equipe do Museu do Meio Ambiente, durante visitas escolares previamente agendadas com o Programa Educativo.

Esta atividade planejada para um potencial grupo visitante foi efetivamente elaborada em parceria com a equipe de educadores do museu, a partir de reuniões realizadas no Jardim Botânico. Dessa maneira, o conjunto de ações pensado para o sistema Revelar está adequado aos dados de realidade daquele ambiente de trabalho.

\section{CULTURA PARTICIPATIVA E MUSEU INCLUSIVO}

Uma lógica de colaboração caracteriza a dinâmica social contemporânea. Pesquisando as relações entre as atuais tecnologias de comunicação e os novos cenários de educação por elas viabilizados, Jenkins e colaboradores (2009, localização 22 de 1115) entendem que vivemos uma "cultura participativa": um cenário com forte apoio para o engajamento cívico e um certo tipo de orientação informal, por meio do qual participantes experientes transmitem conhecimento aos novatos. Segundo os autores, essas propriedades vêm emergindo como fruto da crescente propagação de tecnologias de mídia que tornam possível arquivar, anotar, se apropriar e recircular conteúdo informacional de inúmeras formas.

Em meio a esse panorama cultural, diversos profissionais que trabalham em museus têm articulado discussões com o intuito de investigar as configurações que o museu contemporâneo pode assumir em termos de suas novas possibilidades de interface com o público.

Jim Richardson - um dos organizadores da conferência europeia MusemNext, que trata de inovação e tecnologia em museus - entende que, por meio de uma Web mais social, internautas encontraram suas vozes. Caberia aos profissionais envolvidos na concepção de exposições encorajar seus visitantes a ver o museu como mais um espaço onde eles podem se expressar. Nesse sentido, a Web, enquanto plataforma de criação e compartilhamento de conteúdo e também fórum para colaboração, serviria de referência ao museu da era digital ${ }^{2}$.

O poder da tecnologia digital abriu diversos canais por meio dos quais o museu pôde estabelecer relações com o seu público. Essa relação dialógica com os visitantes, potencializada pelo meio online, encontra-se inserida em uma discussão mais ampla, que diz respeito a uma postura inclusiva por parte dos museus, interpretados como um espaço para o encontro. Nessa abordagem, a museologia é encarada como um

\footnotetext{
2 Jim Richardson, em texto disponível em: http://www.museumnext.org/2010/blog/rethinking-themuseum-for-the-digital-age. Acesso em: 26 mar 2014.
} 
veículo para o diálogo intercultural, oferecendo oportunidades para diferentes formas de expressão social (SCHEINER, 2008, p. 88). A abertura a novos métodos para documentação, preservação e interpretação da diversidade passa, portanto, pelo estreitamento de laços com o público. Nesse sentido, um museu inclusivo demanda profissionais inclusivos, capazes de estabelecer diálogo com os visitantes e prontos a vivenciar novas experiências.

Por essa ótica, apoiar a participação quer dizer estar aberto à possibilidade de que um projeto pode crescer e mudar, após seu lançamento, para além da intenção original da instituição. Assim sendo, esse apoio demanda uma concentração de esforços na elaboração de um sistema que forneça suporte à participação, prevendo a atuação dos agentes envolvidos e as sucessivas etapas de captação de dados, processamento e exibição. Está em questão, portanto, o design de participação em contexto de museus.

\section{DESIGN DE PARTICIPAÇÃO EM MUSEUS}

\subsection{Design de participação $x$ design participativo}

Com o propósito de não deixar dúvidas quanto às acepções dos termos empregados nesta pesquisa, é indispensável explicitar a distinção entre o design de participação (ou design para a participação) e a prática de domínio projetual consagrada como design participativo (design centrado no usuário). Para isso, lançamos mão da contribuição teórica dos autores Russo e Peacock (2009), para quem o

\footnotetext{
"Design de participação" não deve ser confundido com "design participativo", que tem uma história que dura mais tempo, começando como um processo colaborativo dentro de postos de trabalho, particularmente na Escandinávia, nos anos 1960. Design participativo é mais como uma metodologia para garantir que aqueles que são afetados por decisões de design possam exercer influência sobre elas.
}

O design para a participação é, em vez disso, igualmente um ato de fé como um método racional de planejamento. Ele representa e requer uma confiança radical na fluida, imprevisível e aberta dinâmica de comunidade. ${ }^{3}$ (tradução nossa)

Particularmente em contexto de museus, o design de participação envolve a concepção de uma atividade que pressuponha a participação de visitantes, em uma relação de reciprocidade entre museu e público. Nesse sentido, nos cenários concebidos não se pode precisar exatamente os resultados do processo: projetar para a participação significa permitir resultados, mais do que prescrevê-los.

\footnotetext{
3 “' 'Participation design' should not be confused with 'participatory design' which has a longer history, beginning as a collaborative process within workplaces, particularly in Scandinavia in the 1960s. Participatory design is more of a methodology for ensuring those affected by design decisions are able to have input into them.

Designing for participation is, instead, as much an act of faith as a rational planning method. It represents and requires a radical trust in the fluid, unpredictable and open-ended dynamics of community." Angelina Russo and Darren Peacock, Great expectations: sustaining participation in social media spaces.
} 


\subsection{Ecologia de participação e coordenação de ações}

Interessada em explorar as maneiras pelas quais abordagens relacionadas ao design de interação podem ser usadas para encorajar o envolvimento da comunidade em exposições, Salgado $(2009$, p. 67) levanta a seguinte hipótese: ao tornar a comunidade parte da exposição, é possível ampliar e atualizar as perspectivas e discussões a respeito do que é exibido, provendo mais oportunidades para o aprendizado e o compartilhamento de visões de mundo.

Segundo a autora, em um projeto para a participação, elementos como lugares, pessoas (visitantes, profissionais de museus, colaboradores externos) e produtos (mobília, hardware, software, material de divulgação) atuam como componentes de uma ecologia. Nela, o designer não é somente alguém que busca uma solução para um problema específico, mas um ator que mapeia as possibilidades para intervenção (que vão além do projeto de um produto em particular), operando de forma integrada com os outros agentes. Pode-se verificar, portanto, um deslocamento de ênfase que parte dos objetos/peças interativos(as) para a prática da participação em si.

Esta forma de abordar o problema encontra eco nas ideias desenvolvidas por Hindmarsh et al. (2005, p. 33). Pesquisando sobre a concepção de ambientes interativos em espaços públicos, os autores identificam que estes ambientes serão experimentados por pessoas em diferentes níveis de envolvimento. As pessoas serão centrais/periféricas, ativas/passivas, mais dadas a ouvir/mais dadas a observar, assistirão/olharão de relance; as pessoas estarão sozinhas, em casais, em grupos.

Por esse motivo, os pesquisadores advogam que os profissionais de museu precisam fazer esforços combinados para considerar os tipos de atividade nas quais se quer envolver os visitantes, para, então, explorar possíveis disposições de objetos que facilitem tais atividades. O desafio de design, portanto, é o de, cuidadosamente, conceber e organizar esse conjunto de ações.

Dessa forma, podemos tomar um painel interativo, um software/aplicativo desenvolvido para uso dos visitantes e o material de divulgação de uma exposição, como componentes de uma problematização mais ampla, que é o design de participação em museus. As ações de visitantes, pesquisadores, curadores, monitores, designers e educadores, são, igualmente, elementos que contribuem para o sucesso de uma experiência participativa, devendo, portanto, ser tratadas como parte do problema de design.

A seguir, é apresentado o sistema Revelar, elaborado nesta pesquisa com o intuito de investigar o design de participação em contexto museológico, ancorando-se particularmente na realidade de funcionamento do Museu do Meio Ambiente (Jardim Botânico do Rio de Janeiro).

\section{DESCRIÇÃO DO SISTEMA REVELAR}

\subsection{Síntese}

Revelar é um sistema que pressupõe a participação de estudantes de Ensino Médio em uma atividade programada pela equipe do Museu do Meio Ambiente, durante visitas escolares previamente agendadas com o Programa Educativo. A matéria de contribuição dos alunos participantes seria, essencialmente, a fotografia capturada com dispositivos móveis (smartphones). Já a matéria a ser fotografada (registro de informação) seriam objetos presentes no Jardim Botânico - espécimes 
vegetais e animais, monumentos, fontes, lagos - registrados durante trajetos mediados por educadores no arboreto ${ }^{4}$.

É indispensável deixar claro que o sistema foi concebido enquanto projeto, configurando-se como um modelo preliminar. Nele, o Jardim Botânico e o Museu do Meio Ambiente constituem a base real de ancoragem do sistema idealizado. Adequados a essa realidade, foram elaborados elementos projetuais e um cenário de utilização capazes de dar origem a uma efetiva implementação, a um projeto piloto que pode vir a ser executado futuramente.

\subsection{Exercício do olhar}

Essencialmente, a atividade concebida para os estudantes exploraria a palavra como estímulo e a fotografia como expressão. Fragmentos de textos que tratam de questões socioambientais seriam apresentados aos alunos, já com determinadas palavras-chave selecionadas previamente. Basicamente, o exercício consistiria em produzir fotografias que, na opinião dos alunos, expressassem tais palavras, utilizando o arboreto como campo de observação.

Particularmente, as imagens seriam produzidas a partir do uso de dispositivos móveis (smartphones), que são objetos próprios do repertório dos estudantes que se teria como público: adolescentes cursando o Ensino Médio, com faixa etária entre 15 e 17 anos. Habituados à fotografia como registro de eventos cotidianos - tal como manifesta nas redes sociais virtuais - os alunos seriam sensibilizados a pensar em seu potencial como instrumento capaz de expressar um conceito abstrato.

\subsection{Detalhamento da atividade programada}

Em geral, as atividades oferecidas pelo Programa Educativo do Museu do Meio Ambiente às escolas em visitação têm duração total de uma (01) hora, com um número de estudantes que varia entre 30 e 40 jovens. Eventualmente, algumas escolas fazem um agendamento que prevê duas (02) horas a serem despendidas por seus alunos no museu. Nesses casos, o Educativo organiza duas atividades com uma hora de duração cada para o grupo em questão.

Considerando esse dado de realidade, a atividade pensada para o sistema Revelar apresentaria duração prevista de (01) hora, dividindo-se nas quatro etapas seguintes:

- Pré-visita (ambiente escolar);

- Acolhimento (15min);

- Trajeto pelo arboreto (30min);

- Visualização e interação (15min)

\subsubsection{Pré-visita (ambiente escolar)}

Uma vez estabelecido o agendamento da visita ao Museu do Meio Ambiente, a escola transmitiria ao Programa Educativo dados sobre os alunos que participariam da atividade, tais como: nome; idade; série; turma. Essas informações seriam utilizadas pela equipe de educadores para configurar o sistema Revelar, preparando os dispositivos móveis para o uso pelos estudantes.

\footnotetext{
${ }^{4} \mathrm{O}$ arboreto é a porção do complexo do Jardim Botânico onde são cultivadas árvores, arbustos e plantas herbáceas para exibição ao público (coleções vivas); local informalmente referido como parque.
} 
Ainda em sala de aula, os alunos tomariam conhecimento da futura visita. Neste momento, seria exibido à turma um vídeo de curta duração (menos de 5 minutos) explicando a dinâmica da atividade em linhas gerais ${ }^{5}$.

\subsubsection{Acolhimento}

Consideremos um grupo de 30 estudantes chegando ao museu. No acolhimento, eles seriam recebidos pela equipe do Educativo, que Ihes apresentaria dois fragmentos de textos relacionados a temáticas socioambientais (Figura 1). De forma exemplar, podem ser citadas aqui referências fornecidas pela equipe do Educativo: introdução do Tratado de Educação Ambiental para Sociedades Sustentáveis e Responsabilidade Global; fala do escritor e filósofo Leonardo Boff; trecho do livro Educar para uma cultura de sustentabilidade, do pedagogo Moacir Gadotti; preâmbulo da Carta da Terra (ONU); entre outros.

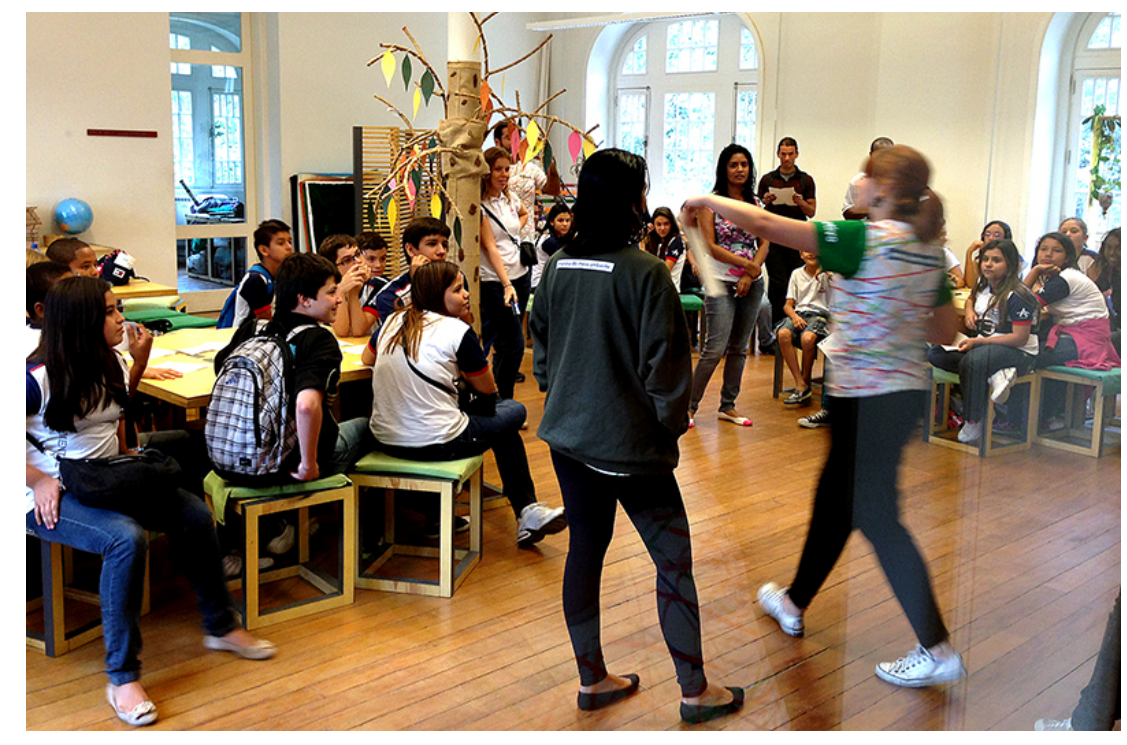

Figura 1 - Educadores realizam acolhimento de turma em atividade similar (elaborado pelo autor, com base na pesquisa realizada)

Em cada um dos fragmentos, três palavras-chave, previamente escolhidas pelos educadores, seriam destacadas: conceitos que não apresentassem referencialidade imediata com objetos do mundo físico, mas que exercitassem a capacidade de abstração do aluno, estimulando a sua imaginação. Nesse sentido, termos como "árvore", "pássaro" e "água" não seriam selecionados, cedendo espaço para outros, tais como "respeito", "transformação", "rebeldia".

Metade da turma trabalharia com as palavras de um dos fragmentos de texto e a outra metade com as do outro. Cada um dos grupos de 15 alunos seria dividido em trios, totalizando 5 trios por fragmento. Cada trio receberia um dispositivo móvel emprestado pela equipe do museu, já com o aplicativo Revelar instalado e operando. O primeiro passo na sequência de ações do aplicativo seria a seleção do fragmento de

\footnotetext{
${ }^{5}$ Os vídeos mencionados neste artigo foram efetivamente desenvolvidos na pesquisa, e as figuras 2-4 foram deles retiradas. Eles estão disponibilizados para visualização no seguinte endereço eletrônico: http://www.julianokestenberg.com/projects/reveal.php.
} 
texto a ser explorado, o que já teria sido realizado pela equipe de educadores antes da entrega dos dispositivos aos alunos.

Em seguida, os estudantes seriam apresentados ao desafio da atividade: acompanhados pelos mediadores, eles iriam ao arboreto para tirar fotografias que expressassem as palavras-chave previamente selecionadas.

Seria exibido à turma, então, um novo vídeo de curta duração. Este trataria da navegação no aplicativo Revelar, explicitando aos alunos o passo-a-passo para a captura de fotos e seu envio ao sistema. Durante o acolhimento, ocorreria, ainda, uma gravação de áudio que registraria o contexto de apresentação da atividade aos estudantes.

\subsubsection{Trajeto pelo arboreto}

Logo após o acolhimento, o grupo realizaria um trajeto pelo arboreto, no qual os alunos fariam o registro fotográfico de objetos/cenas que julgassem exprimir os conceitos apresentados inicialmente. Essas fotos revelariam as interpretações dos estudantes, baseadas no repertório de cada um deles.

De posse do dispositivo, um estudante verificaria as três palavras do texto selecionado. Em seguida, ele se identificaria, informando seu nome por meio de um comando de voz. O fragmento de áudio resultante dessa ação seria salvo pelo aplicativo e submetido ao sistema Revelar, para ser utilizado na etapa de interação, quando do retorno do grupo ao museu.

Cada aluno teria cerca de $10 \mathrm{~min}$ para tirar suas fotos, que apresentariam formato quadrado. O número limite de fotografias para cada aluno-autor seria seis; caso quisesse tirar mais fotos, o estudante deveria excluir algumas daquelas já produzidas. Passados $10 \mathrm{~min}$, o aluno seria requisitado a estabelecer a associação entre suas fotos e as palavras-chave do texto em questão. Para isso, ele selecionaria uma de suas imagens na galeria e pronunciaria a palavra-chave que desejasse associar a ela. Após confirmada a submissão, a imagem seria carregada para o servidor do sistema Revelar, em tarefa executada pelo aplicativo em plano de fundo (Figura 2).

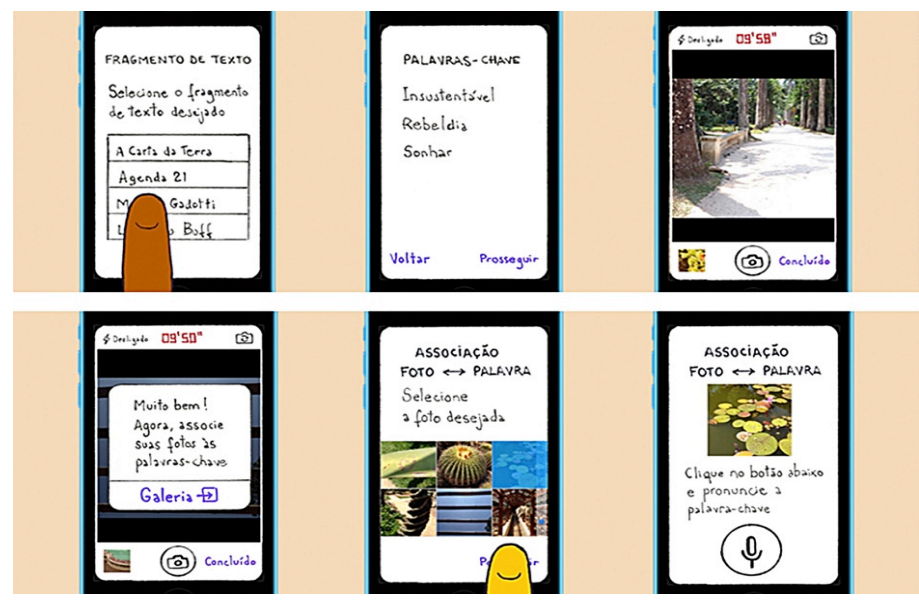

Figura 2 - llustrações esboçam telas do aplicativo Revelar ${ }^{6}$ (elaborado pelo autor, com base na pesquisa realizada)

\footnotetext{
${ }^{6}$ É importante deixar claro que as ilustrações das telas têm por objetivo evidenciar a arquitetura da informação envolvida no funcionamento do aplicativo. Definitivamente, elas não são apresentadas como versões finais, mas sim como ilustrações do fluxo operacional.
} 
Novas associações seriam feitas até que cada uma das três palavras-chave tivesse sua foto expressiva correspondente. Com sua missão cumprida, o estudante passaria o dispositivo a um de seus colegas de trio, que daria início, então, a seu processo de captura. $O$ universo de imagens a ser considerado giraria em torno de 90 fotos. Ao final do trajeto, os mediadores conduziriam os alunos de volta ao museu para a etapa de visualização do material produzido.

\subsubsection{Visualização e interação}

Esta etapa aconteceria em uma sala equipada com um aparelho projetor e com uma interface multi-toque (mesa), com um microfone. As fotos dos alunos seriam projetadas sobre um painel, que constituiria a ambiência dos dados visualizáveis.

A seção conclusiva estaria divida nas três seguintes fases: a) Passeio visual; b) Interação; c) Fechamento.

Durante o passeio visual, valendo-se do atributo de geolocalização, as imagens produzidas pelo grupo apareceriam no painel sobre um mapa do Jardim Botânico, justamente nos pontos onde houvessem sido capturadas (Figura 3).

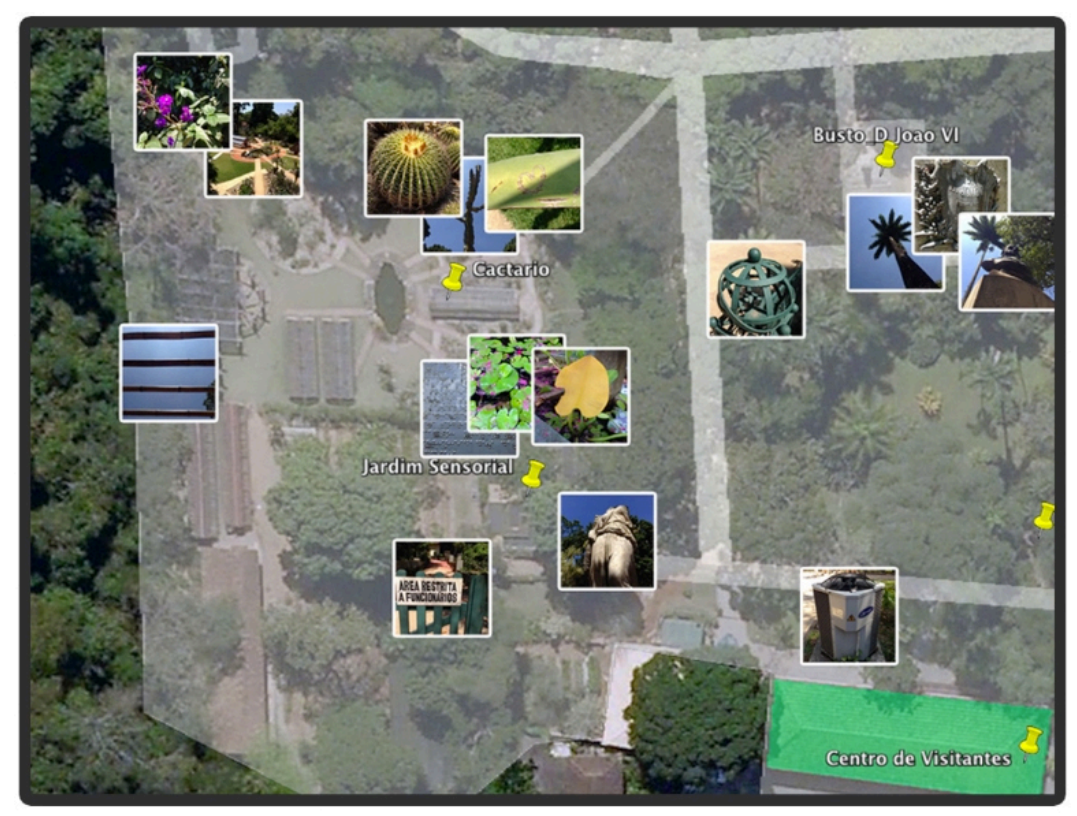

Figura 3 - Fotografias seriam exibidas sobre mapa do Jardim Botânico (elaborado pelo autor, com base na pesquisa realizada)

Exibindo uma vista de topo do arboreto, o painel permitiria que alunos e educadores reconhecessem o trajeto percorrido. Nesse percurso visual, algumas imagens do trajeto ganhariam destaque, acompanhadas da reprodução da voz de seus respectivos autores. Cada estudante observaria, então, as fotos produzidas por seus colegas. Juntamente com a exibição das fotos, seria reproduzido como som ambiente o áudio gravado ainda no acolhimento, estabelecendo, assim, a conexão com o material que lhes teria servido de inspiração para a produção das imagens. 
Em seguida, teria início a fase de interação. Manipulando a mesa multi-toque, um dos educadores acionaria um comando que faria com que o sistema escolhesse, aleatoriamente, uma imagem produzida e a evidenciasse no painel (Figura 4).
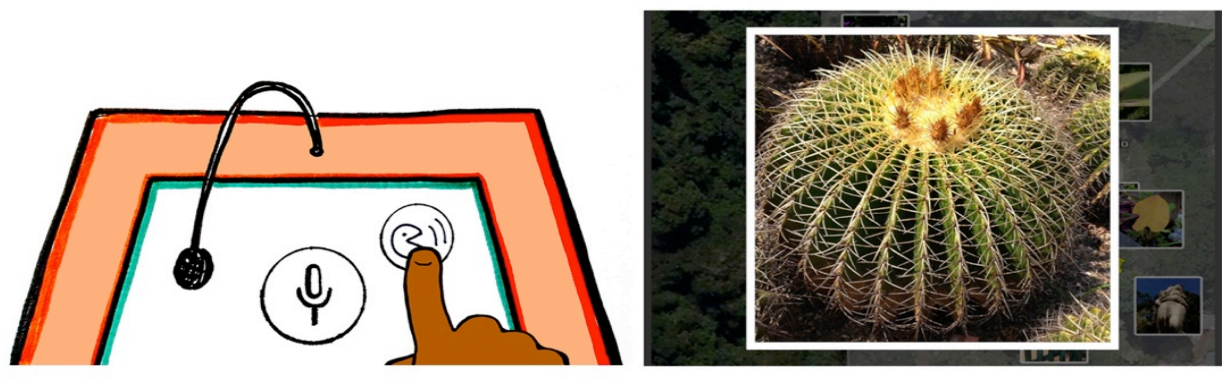

Figura 4 - Após comando na mesa, uma foto ganharia destaque no painel (elaborado pelo autor, com base na pesquisa realizada)

Seu autor seria, então, convidado a falar brevemente para o grupo sobre a foto tirada. Esse processo se repetiria algumas vezes, até a realização de uma conversa final sobre a atividade vivenciada pelos alunos. Neste fechamento, os educadores fariam uma rápida revisão do processo, utilizando as imagens produzidas pela turma como apoio visual da mediação. Poderiam ser estabelecidas conexões entre os temas trabalhados a partir das justificativas apresentadas pelos estudantes, os incentivando a uma auto-avaliação. A equipe de educadores comunicaria ao grupo que as fotos geradas seriam incorporadas ao banco de imagens do sistema Revelar, e estariam, também, disponíveis para visualização no website do Museu do Meio Ambiente.

\subsection{Aspectos educacionais}

A atividade programada para os estudantes apresentaria alguns aspectos educacionais aqui destacados. Seriam exercitados a cooperação e a capacidade de negociação entre os alunos, uma vez que o conjunto de fotografias resultante seria fruto de uma ação em equipe, na qual cada estudante teria contribuído com uma parcela do todo. Habilidades pessoais e sociais como tomada de decisão, manifestação de opinião e fala em público também seriam trabalhadas no decorrer do processo concebido.

Especialmente durante o trajeto, os estudantes seriam estimulados a perceber a sua relação com o seu entorno, e os mediadores reforçariam o conceito de interdependência entre os seres vivos para a preservação do meio ambiente.

A atividade proveria aos alunos oportunidades de se mostrarem criativos. Aprendendo em conjunto, eles veriam, finalmente, suas fotografias integradas ao conteúdo exposto no museu, sentindo-se parte dele (senso de pertencimento).

\section{CONCLUSÃO}

\subsection{Trabalhos futuros}

\subsubsection{Visualização de dados: sistema interno}

Uma possibilidade de trabalho futuro seria o desenvolvimento de um sistema de visualização dos dados gerados ao longo do tempo por várias turmas. Este sistema, 
de caráter analítico, seria uma plataforma de consulta/controle interno, atendendo ao público de educadores e administradores do Museu do Meio Ambiente.

A partir de centenas de fotos produzidas por alunos de idades e escolas diferentes, poderiam ser visualizados dados como, por exemplo: a) quais pontos/monumentos do arboreto foram mais fotografados (concentração de imagens/clusters); b) quais os períodos do ano mais produtivos, em termos de imagens registradas?; c) quais os horários do dia que concentraram maior número de fotos?; d) quais regiões da cidade do Rio de Janeiro estão representadas pelas escolas que visitaram o museu?

Poderiam ser, ainda, estabelecidas algumas comparações: a) como uma mesma palavra-chave foi explorada por alunos de escolas diferentes, em termos da natureza das imagens?; b) como uma mesma palavra foi explorada em diferentes épocas do ano? (em função das estações do ano/ciclos de desenvolvimento dos espécimes vegetais ou das obras de manutenção realizadas no arboreto).

\subsubsection{Expansão da proposta}

Em uma perspectiva de expansão da proposta, o sistema poderia extrapolar o contexto da atividade programada, contemplando o público que espontaneamente visita o Jardim Botânico. Certamente, isso implicaria em mudanças no funcionamento do aplicativo móvel, nos recursos de visualização e interação no museu, e, principalmente, em elaborar estratégias de comunicação capazes de atrair pessoas interessadas em participar da proposta. Permaneceria, no entanto, o caráter essencialmente colaborativo da atividade.

\subsection{Considerações finais}

O passo seguinte à elaboração deste modelo preliminar é a realização de testes operacionais junto ao Museu do Meio Ambiente, capazes de avaliar o funcionamento do sistema, no que diz respeito tanto aos seus aspectos técnicos quanto aos educacionais.

\subsubsection{Interdisciplinaridade}

Pensar em um sistema como Revelar significa considerar os papéis que cada um dos agentes envolvidos irão desempenhar: os alunos, que tirarão as fotografias; os professores, que orientarão o grupo; a equipe de educadores do museu, que coordenará a atividade; os designers e desenvolvedores de software, que trabalharão diretamente com a interface do aplicativo e do painel e com o banco de imagens. Significa também atentar para a coesão das distintas etapas do processo (acolhimento, trajeto, visualização e interação) no sentido de um funcionamento integrado e cíclico.

Fica evidente, portanto, que o desenvolvimento de um projeto dessa natureza demanda competências profissionais diversas. Nesse sentido, o trabalho em parceria com o Museu do Meio Ambiente, considerando a experiência de suas equipes na elaboração de ações educativas, foi de extrema importância, uma vez que permitiu o intercâmbio de ideias entre profissionais com formações distintas, tais como: Museologia, Educação, Pedagogia, Design, Engenharia.

Esse dado de realidade que caracterizou o processo de desenvolvimento do sistema Revelar ilustra o pensamento de autores que entendem a prática do design como uma atividade essencialmente interdisciplinar. É papel do próprio designer o 
exercício de identificar possibilidades de fundamentação e ampliação de seus métodos e teorias. Dessa forma, a flexibilização de barreiras disciplinares através do diálogo com outras fontes do saber torna-se indispensável, tendo como resultado a fertilização do design enquanto área de conhecimento e atuação (COUTO, 2006, p. 77-8).

\subsubsection{Vivacidade}

As perspectivas de funcionamento do museu na contemporaneidade acenam com a dinâmica de uma instituição viva, em um terreno com claras oportunidades para o exercício do design. A abertura para a participação dos visitantes, encarada como uma concepção de interação no museu, se apresenta como estratégia capaz de criar um senso de pertencimento na relação entre público e instituição, suscitando dimensões significativas para a visita, seja ela presencial e/ou virtual.

Tanto o espaço físico do museu quanto a sua extensão na Web seriam atravessados pelo mesmo sistema de visualização qualitativa e quantitativa de dados, possibilitando ao visitante a experiência de situar-se ao mesmo tempo em um espaço físico e em um espaço virtual. Tudo isto leva a uma ampliação de espaço e de tempo.

$\mathrm{E}$, neste modelo, o museu tende a reinventar-se, somando à função de repositório do conhecimento humano o papel de suporte a atividades criativas e à conexão social.

\section{REFERÊNCIAS}

COUTO, Rita Maria de Souza. Reflexões sobre a natureza e a vocação interdisciplinar do design. In: LIMA, Guilherme Cunha (Org.). Textos Selecionados de Design 1. Rio de Janeiro: PPDESDI-UERJ, 2006. 200 p. p. 51-82.

HINDMARSH, Jon et al. Creating assemblies in public environments: social interactions, interactive exhibits and CSCW. Computer Supported Cooperative Work (CSCW), 2005, v. 14 (1), p. 1-41.

JENKINS, Henry (P.I.) et al. Confronting the challenges of participatory culture: media education for the 21st century. Cambridge: MIT Press, 2009. [Kindle Edition]

RUSSO, Angelina; PEACOCK, Darren. Great expectations: sustaining participation in social media spaces. In: TRANT, Jennifer; BEARMAN, David (Ed.). Proceedings of the Museums and the Web 2009. Toronto: Archives and Museum Informatics, 2009. Disponível em: <http://www.museumsandtheweb.com/mw2009/papers/russo/russo.html>. Acesso em: 19 mar. 2013.

SALGADO, Mariana. Designing for an Open Museum: an exploration of content creation and sharing through interactive pieces. 2009. 230 p. Tese (Doutorado em Design) - University of Art and Design Helsinki, Helsinki, 2009.

SCHEINER, Tereza Cristina. Museum and Museology: changing roles - or changing paradigms? In: ICOFOM ANNUAL SYMPOSIUM - Museums, Museology and Global Communications, 31., 2008, Changsha. Anais XXXI ICOFOM 2008. Changsha, China: ICOFOM/ICOFOM LAM, 2008. p. 81-89 (ICOFOM Study Series - ISS 37).

SIMON, Nina. The participatory museum. Santa Cruz, USA: Museum 2.0, 2010. [Kindle Edition] 